\title{
Identification of a novel synthetic lethality of combined inhibition of hedgehog and PI3K signaling in rhabdomyosarcoma
}

\author{
Ulrike Graab', Heidi Hahn², Simone Fulda ${ }^{1,3,4}$ \\ ${ }^{1}$ Institute for Experimental Cancer Research in Pediatrics, Goethe-University, Frankfurt, Germany \\ ${ }^{2}$ Institute of Human Genetics, University Medical Center, Goettingen, Germany \\ ${ }^{3}$ German Cancer Consortium (DKTK), Heidelberg, Germany \\ ${ }^{4}$ German Cancer Research Center (DKFZ), Heidelberg, Germany \\ Correspondence to: \\ Simone Fulda, e-mail: simone.fulda@kgu.de
}

Keywords: apoptosis, hedgehog, PI3K, rhabdomyosarcoma

Received: October 15, $2014 \quad$ Accepted: November 12, $2014 \quad$ Published: March 06, 2015

\section{ABSTRACT}

We previously reported that aberrant HH pathway activation confers a poor prognosis in rhabdomyosarcoma (RMS). Searching for new treatment strategies we therefore targeted $\mathrm{HH}$ signaling. Here, we identify a novel synthetic lethality of concomitant inhibition of HH and PI3K/AKT/mTOR pathways in RMS by GLI1/2 inhibitor GANT61 and PI3K/mTOR inhibitor PI103. Synergistic drug interaction is confirmed by calculation of combination index (CI < 0.2$)$. Similarly, genetic silencing of GLI1/2 significantly increases PI103-induced apoptosis. GANT61 and PI103 also synergize to induce apoptosis in cultured primary RMS cells emphasizing the clinical relevance of this combination. Importantly, GANT61/PI103 cotreatment suppresses clonogenic survival, three-dimensional sphere formation and tumor growth in an in vivo model of RMS. Mechanistic studies reveal that GANT61 and PI103 cooperate to trigger caspase-dependent apoptosis via the mitochondrial pathway, as demonstrated by several lines of evidence. First, GANT61/PI103 cotreatment increases mRNA and protein expression of NOXA and BMF, which is required for apoptosis, since knockdown of NOXA or BMF significantly reduces GANT61/PI103-induced apoptosis. Second, GANT61/PI103 cotreatment triggers BAK/BAX activation, which contributes to GANT61/PI103-mediated apoptosis, since knockdown of BAK provides protection. Third, ectopic expression of BCL-2 or non-degradable phospho-mutant MCL-1 significantly rescue GANT61/PI103-triggered apoptosis. Fourth, GANT61/PI103 cotreatment initiate activation of the caspase cascade via apoptosome-mediated cleavage of the initiator caspase-9, as indicated by changes in the cleavage pattern of caspases (e.g. accumulation of the caspase-9 p35 cleavage fragment) upon addition of the caspase inhibitor zVAD.fmk. Thus, combined GLI1/2 and PI3K/mTOR inhibition represents a promising novel approach for synergistic apoptosis induction and tumor growth reduction with implications for new treatment strategies in RMS.

\section{INTRODUCTION}

RMS, the most common pediatric soft-tissue sarcoma, can be classified into two major subtypes, i.e. alveolar (ARMS) and embryonal (ERMS), according to the mutation status and histological features $[1,2]$. One common mutation in RMS consists in the loss of heterozygosity $(\mathrm{LOH})$ at chromosomal region $9 \mathrm{p} 22$, including the patched homolog (PTCH) locus [3].
PTCH mutations also give rise to the naevoid basal cell carcinoma syndrome (NBCCS), known as Gorlin syndrome, which is characterized by predispositions to develop basal cell carcinomas (BCC), medulloblastoma (MB) and RMS [4-6]. Mice heterozygous for PTCH develop many of the features characteristic for NBCCS, including RMS $[5,7]$. PTCH is an essential component of the $\mathrm{HH}$ signaling pathway, which is activated in RMS i.e. via loss of chromosomal region 9 p22 or by 
amplification of the 12q13-15 region including the GLI1 gene [3].

Canonical HH signaling pathway is activated via binding of one of the ligands, e.g. sonic hedgehog (SHH), to the transmembrane receptor PTCH. This leads to the inactivation of PTCH and subsequently to the release of the second transmembrane receptor smoothened (SMO) [8]. $\mathrm{SMO}$ in turn modulates expression and/or post-translational processing of the three GLI transcription factors. GLI1 and GLI2 act mainly as transcriptional activators, while GLI3 functions as a transcriptional repressor [9]. The balance between GLI activator and repressor forms results in expression of $\mathrm{HH}$ target genes, including GLII and PTCH [10]. Besides the canonical HH pathway, GLI proteins can also be activated in a non-canonical and SMO-independent manner via phosphorylation by PI3K/AKT [11, 12], mTOR/ S6 [13], RAS [11, 14] or MAPK/ERK [15].

Crosstalk between $\mathrm{HH}$ and PI3K/AKT/mTOR signaling has been observed in different tumor entities. In esophageal cancer, mTOR/S6 kinase signaling was shown to phosphorylate GLI1, promoting its transcriptional activity and tumor growth $[13,16]$. In breast cancer, PI3K/ AKT signaling was reported to protect key elements of the HH signaling pathway including GLI1 from proteasomal degradation [17].

Programmed cell death is a fundamental cellular program that is critical for maintaining tissue homeostasis [18]. Two major apoptosis signaling pathways have been characterized, i.e. the extrinsic, receptor-mediated and the intrinsic, mitochondria-mediated pathway [19]. Mitochondrial apoptosis is controlled by various factors including BCL-2 family proteins, which comprise antiapoptotic proteins such as BCL-2, BCL- $\mathrm{X}_{\mathrm{L}}$ and MCL-1 as well as proapoptotic proteins like $\mathrm{BAK}, \mathrm{BAX}$ and BH3-only proteins (i.e. BID, BIM, BMF and NOXA) [20]. Activation of BAX and BAK, for example upon binding of $\mathrm{BH} 3$-only proteins, leads to mitochondrial outer membrane permeabilization and release of mitochondrial intermembrane space proteins such as cytochrome $\mathrm{C}$ that engages caspase-9 activation within the apoptosome complex [21].

Since we previously identified aberrant activation of the HH pathway as a new poor prognostic factor in RMS [22], we aimed at therapeutic targeting of this signaling cascade in the present study. In view of mounting evidence showing that canonical as well as non-canonical mechanisms can cause $\mathrm{HH}$ activation, we inhibited $\mathrm{HH}$ signaling at different levels alone and in combination with inhibition of $\mathrm{HH}-$ interacting pathways such as PI3K/AKT/mTOR signaling.

\section{RESULTS}

\section{GANT61 and PI103 synergize to induce apoptosis in RMS cells}

To investigate the role of the $\mathrm{HH}$ signaling pathway in RMS we initially evaluated expression levels of different HH components in a panel of ARMS and ERMS cell lines. HH pathway activation was documented by broad expression of GLI1 and GLI2, whereas GLI3 and $P T C H$ were differentially regulated and SHH expression was not detectable in most cell lines (Fig. S1A).

To represent the two major histological subtypes of RMS we selected the two alveolar RMS cell lines RMS13 and RH30, which contain an amplification of GLI1 $[23,24]$ and the embryonal RMS cell lines RD and TE381.T. Importantly, we discovered that the GLI1/2 inhibitor GANT61 and the dual PI3K/mTOR inhibitor PI103 synergistically induced apoptosis in all RMS cell lines (Fig. 1A). Calculation of combination index (CI) illustrates the synergism of this combination treatment (Suppl. Table S1). Parallel experiments showed that GANT61 and PI103 cooperated to suppress mRNA levels of HH target genes GLI1, GLI2 and PTCH (Fig. S2A) and to reduce phosphorylation of key components of the PI3K/AKT/mTOR pathway such as AKT, S6 and 4E-BP1 (Fig. S2B). To ensure that this finding is not restricted to established cell lines, we used primary cultured RMS cells derived from a tumor sample. Similarly, GANT61 and PI103 synergized to trigger apoptosis in primary cultured RMS cells (Fig. 1A), underlining the clinical relevance of this combination. By comparison, treatment with the SMO inhibitor GDC-0449 at micromolar concentrations exerted little effects on cell viability and $\mathrm{HH}$ target gene expression (Fig. S1B) and failed to cooperate with PI103 to induce apoptosis in RMS cells (Fig. S1C).

In addition to pharmacological inhibition of GLI1/2 by GANT61, we also tested a genetic approach by concomitant knockdown of GLI1/2 via siRNA. Similarly, GLI1/2 silencing significantly increased PI103-induced apoptosis (Fig. S3A). In addition to PI103 the dual PI3K/mTOR inhibitor BEZ235, the PI3K inhibitor GDC-0941 and the mTOR inhibitors RAD001 and AZD8055 all significantly increased GANT61-induced apoptosis (Fig. S4). This indicates that inhibition of PI3K/AKT/mTOR signaling at different levels interacts with HH pathway inhibition to trigger apoptosis in RMS cells. Together, this set of experiments shows that combined inhibition of GLI1/2 and $\mathrm{PI} 3 \mathrm{~K} / \mathrm{mTOR}$ synergizes to induce apoptosis in RMS.

\section{GANT61/PI103 cotreatment cooperates to trigger caspase cleavage and caspase-dependent apoptosis}

To investigate the underlying molecular mechanisms of the synergistic interaction of GANT61 and PI103 we analyzed activation of caspases involved in intrinsic and extrinsic apoptosis signaling. GANT61 and PI103 cooperated to trigger cleavage of caspase- 9 into p37 and p35 fragments, caspase- 3 into p 17 and p12 active cleavage fragments and caspase- 8 into p43 and p41 fragments (Fig. 2A). To test whether caspase activity is necessary for apoptosis we used the broad-range caspase inhibitor 
RD

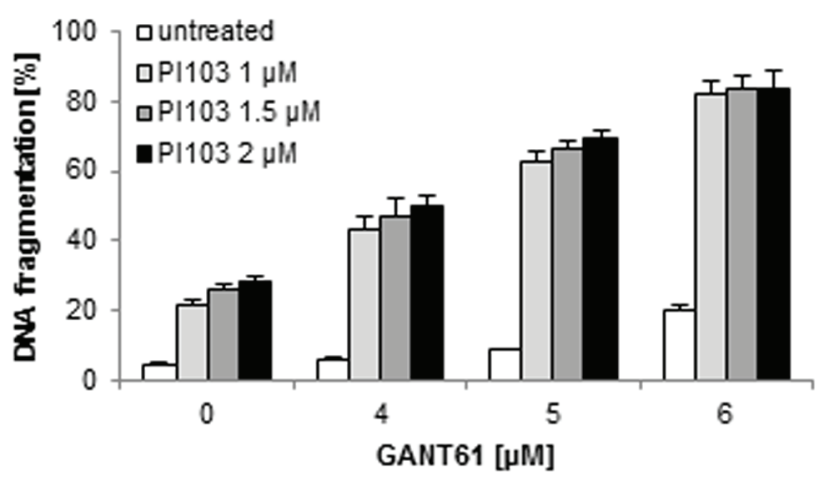

RMS13

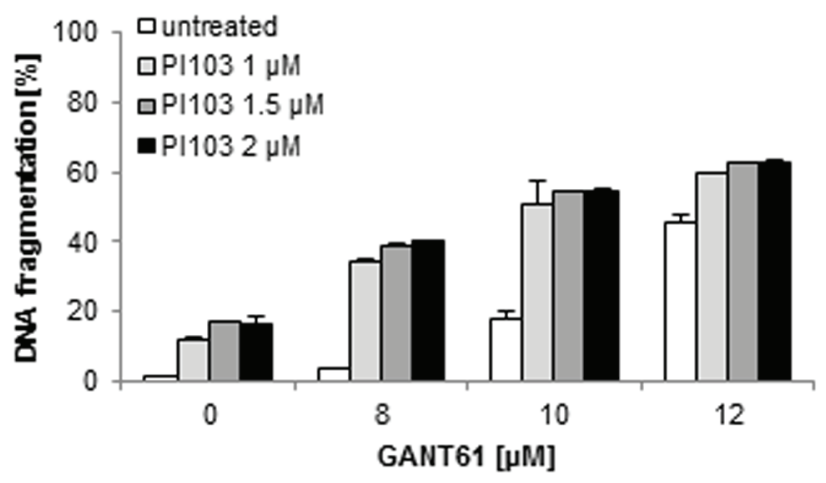

VJ

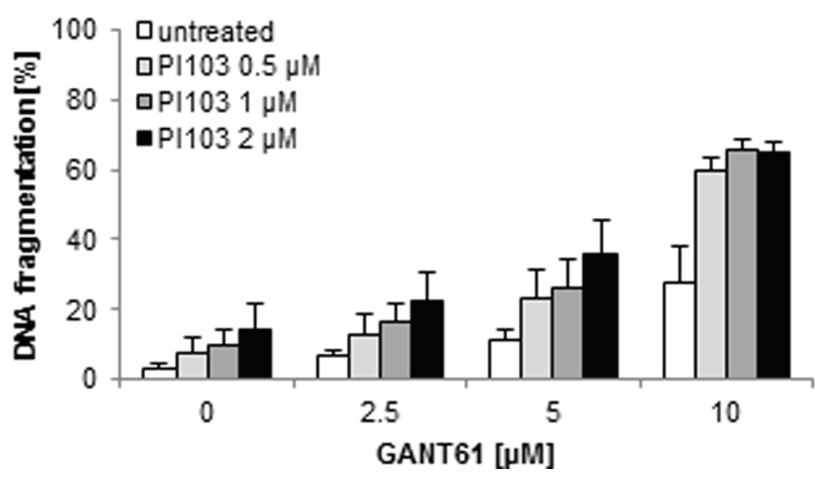

TE381.T

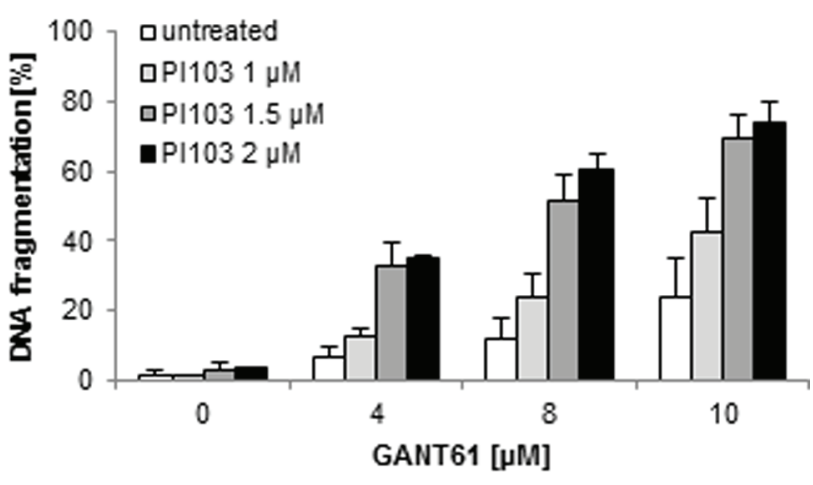

RH30

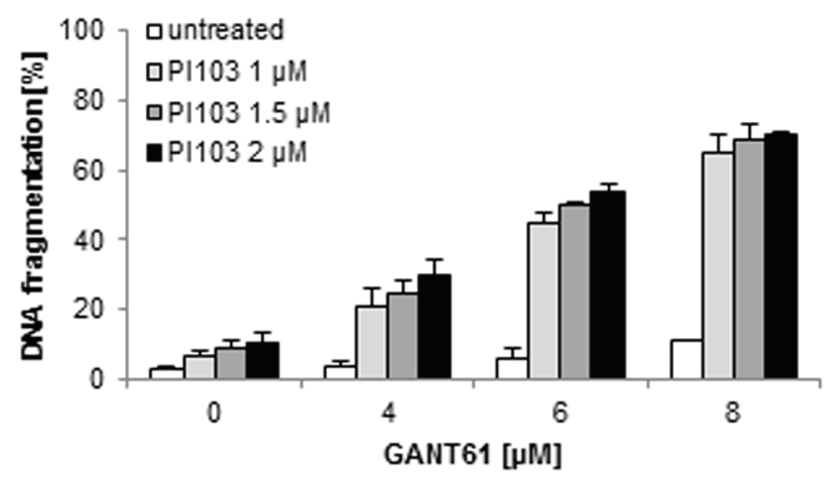

Figure 1: GANT61 and PI103 synergize to induce apoptosis in RMS cells. RD, TE381.T, RMS13, RH30 and VJ cells were treated for 72 hours with indicated concentrations of PI103 and/or GANT61. Apoptosis was determined by DNA fragmentation of propidium iodide (PI)-stained nuclei using flow cytometry. Mean + S.D. of three independent experiments performed in triplicate are shown. Corresponding CI values are shown for all cell lines in Suppl. Table 1.

N-benzyloxycarbonyl-Val-Ala-Asp-fluoromethylketone (zVAD.fmk). Addition of zVAD.fmk significantly reduced GANT61/PI103-induced apoptosis in all cell lines except RH30 cells (Fig. 2B). Interestingly, zVAD.fmk treatment changed the cleavage pattern of caspase- 9 and -3 with accumulation of caspase- 9 p35 and caspase- 3 p 19 cleavage fragments, whereas caspase- 8 cleavage was completely blocked (Fig. 2A). These findings point to apoptosomemediated cleavage of caspase- 9 via induced proximity independently of caspase activity and subsequent initial cleavage of caspase-3 by caspase- 9 , while autoproteolytic processing of caspase- 3 is blocked by zVAD.fmk. Kinetic analysis revealed that GANT61/PI103-induced apoptosis started around 24 hours in TE381.T and VJ cells and slightly later in RD, RMS13 and RH30 cells (Fig. 2C). Taken together, these findings indicate that GANT61/ PI103 cotreatment cooperates to induce caspase activation and caspase-dependent apoptosis. 

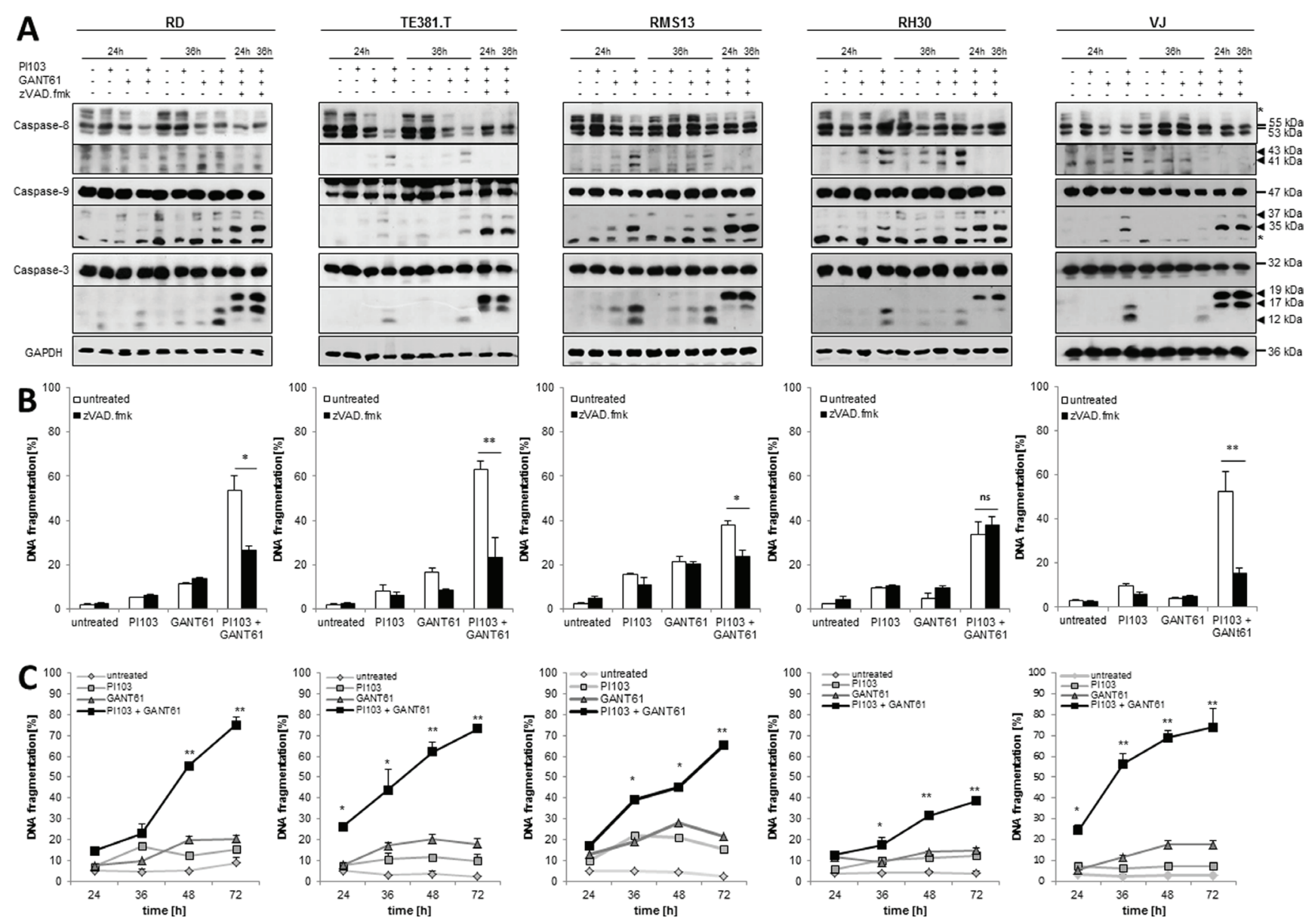

Figure 2: GANT61/PI103 cotreatment cooperates to trigger caspase cleavage and caspase-dependent apoptosis. RD, TE381.T, RMS13, RH30 and VJ cells were treated for indicated times (A, C) or for 48 hours (B) with $1 \mu$ M PI103 and/or GANT61 (RD $6 \mu \mathrm{M}$; TE381.T $8 \mu \mathrm{M}$; RMS13 $10 \mu \mathrm{M}$; RH30 $8 \mu \mathrm{M}$; VJ $8 \mu \mathrm{M}$ ) in the presence or absence of $50 \mu \mathrm{M}$ zVAD.fmk (A, B). In A, caspase activation was analyzed by Western blotting (asterisks indicate unspecific bands) and active cleavage fragments are indicated by arrow heads. (B and C) apoptosis was determined by DNA fragmentation of PI-stained nuclei using flow cytometry. Mean + S.D. of three independent experiments performed in triplicate $(\mathrm{B}, \mathrm{C})$ or representative blots $(\mathrm{A})$ are shown; ${ }^{*} p<0.05 ; * * p<0.01$.

\section{GANT61/PI103 cotreatment increases NOXA and BMF expression}

Since the observed cleavage pattern of caspases points to engagement of the mitochondrial apoptotic pathway by GANT61/PI103 cotreatment, we analyzed the effects of GANT61 and PI103 on expression levels of pro- and antiapoptotic BCL-2 family proteins, which play an important role in regulating mitochondrial apoptosis. Interestingly, treatment with GANT61 alone or in combination with PI103 led to upregulation of the proapoptotic protein NOXA (Fig. 3A), which was accompanied by upregulation of NOXA mRNA by GANT61/PI103 cotreatment in RD and RH30 cells (Fig. 3B). In addition, treatment with PI103 alone or in combination with GANT61 caused a substantial upregulation of BMF mRNA and protein levels (Fig. 3A, 3B). Furthermore, GANT61/PI103 cotreatment increased expression of BIM and reduced MCL-1 protein levels in RH30 cells, whereas it had little effects on expression of BCL-2, BCL-X $\mathrm{L}_{\mathrm{L}}$ BAX and BAK (Fig. S5). This suggests that GANT61/PI103 cotreatment shifts the ratio of pro- and antiapoptotic BCL-2 proteins towards apoptosis.

\section{NOXA and BMF are required for GANT61/ PI103-induced apoptosis}

To investigate the functional involvement of NOXA and BMF in apoptosis induction we knocked down these proteins by siRNA (Fig. S6). NOXA silencing significantly reduced GANT61/PI103-induced apoptosis in all cell lines and BMF knockdown significantly decreased apoptosis in all but RH30 cells (Fig. 4A). Simultaneous knockdown of both NOXA and BMF led to a further significant reduction of GANT61/PI103-induced apoptosis in RMS13 cells (Suppl. Table S2). These findings demonstrate that NOXA and BMF contribute to GANT61/PI103-induced apoptosis. 
A
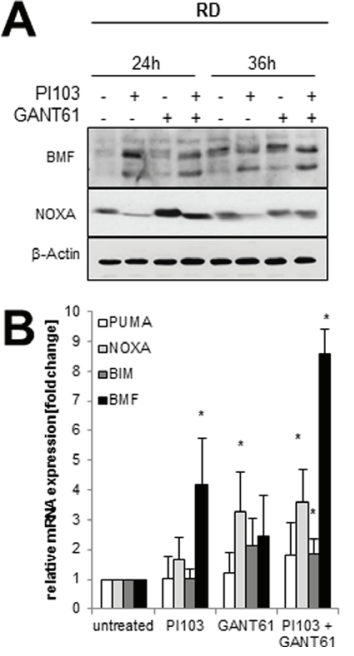
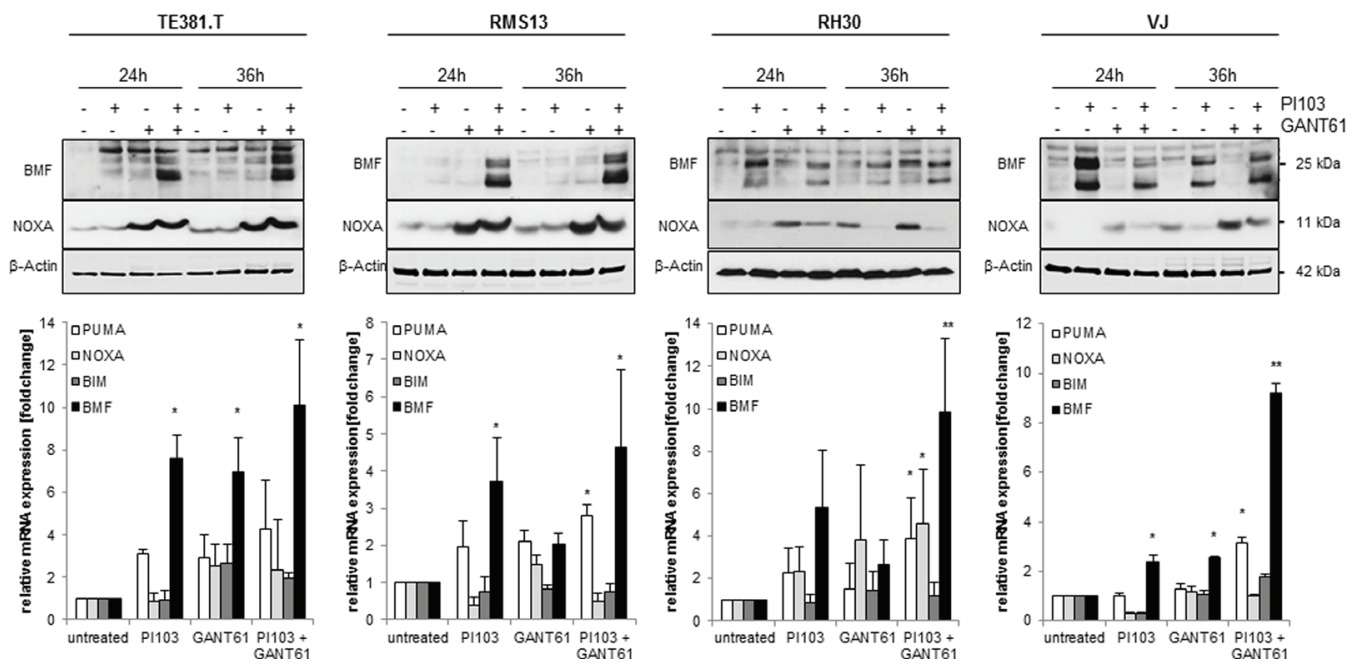

Figure 3: GANT61/PI103 cotreatment increases NOXA and BMF expression. RD, TE381.T, RMS13, RH30 and VJ cells were treated with $1 \mu \mathrm{M}$ PI103 and/or GANT61 (RD $6 \mu \mathrm{M}$; TE381.T $8 \mu \mathrm{M}$; RMS13 $10 \mu \mathrm{M}$; RH30 $8 \mu \mathrm{M}$; VJ $8 \mu \mathrm{M}$ ) for indicated times (A) or 24 hours (B) A, protein expression of BMF and NOXA was analyzed by Western blotting. B, mRNA levels of pro-apoptotic BCL-2 proteins were determined by qRT-PCR. Mean + S.D. of three independent experiments performed in triplicate (B) or representative blots (A) are shown; $* p<0.05 ; * *<0.01$ comparing treated to untreated cells.

\section{GANT61/PI103-mediated BAX/BAK activation is required for apoptosis}

Next, we investigated the question whether the observed upregulation of NOXA and BMF causes activation of BAX and BAK. To this end, we immunoprecipitated BAK and BAX by conformationspecific antibodies, which specifically bind to their activated forms. Indeed, treatment with GANT61 and/ or PI103 resulted in activation of BAX and/or BAK (Fig. 5A). Importantly, genetic knockdown of BAK by siRNA (Fig. S7) significantly reduced GANT61/ PI103-induced apoptosis (Fig. 5B). These experiments demonstrate that GANT61/PI103-mediated BAX/BAK activation is required for apoptosis.

\section{Overexpression of BCL-2 or phospho-mutant MCL-1 rescues GANT61/PI103-induced apoptosis}

To confirm the requirement of the mitochondrial pathway for GANT61/PI103-induced apoptosis, we overexpressed BCL-2 or a non-degradable phosphodeficient MCL-1 mutant [25]. Overexpression of BCL-2 significantly decreased GANT61/PI103-induced apoptosis, attenuated cleavage of caspase- $3,-8$ and -9 and prevented GANT61/PI103-induced activation of BAX (Fig. 6A-6C). Also, ectopic expression of MCL-1 mutant significantly decreased GANT61/PI103-induced apoptosis (Fig. 6D). Vice versa, knockdown of MCL-1 via siRNA significantly increased GANT61/PI103-induced apoptosis (Fig. 6E). These findings confirm that signaling via an intact mitochondrial pathway is required for GANT61/ PI103-induced apoptosis.

\section{GANT61 and PI103 cooperate to suppress clonogenic survival, sphere formation and tumor growth in vivo}

Next, we investigated the effects of GANT61/ PI103 co-treatment on clonogenic survival and threedimensional (3D) tumor growth. GANT61 and PI103 cooperated to significantly reduce long-term clonogenic survival of RMS cells compared to either agent alone or to control (Fig. 7A, 7B). Also, GANT61/PI103 co-treatment significantly decreased sphere formation in a 3D culture model (Fig. 7C). Finally, we tested the in vivo antitumor activity of GANT61/PI103 co-treatment using the chicken CAM model, an established model for tumor growth [26]. To this end, RMS cells were seeded on the CAM of chicken embryos and allowed to form tumors followed by treatment with GANT61 and/or PI103 for three days. Importantly, GANT61 and PI103 acted in concert to reduce tumor growth (Fig. 7D, 7E). These experiments show that GANT61/PI103 co-treatment suppresses clonogenic survival, sphere formation and RMS growth in vivo.

\section{DISCUSSION}

Searching for new treatment strategies in RMS, we focused on the HH signaling pathway, since we previously reported that aberrant activation of this pathway confers a poor prognosis in RMS [22]. There is accumulating 
RD

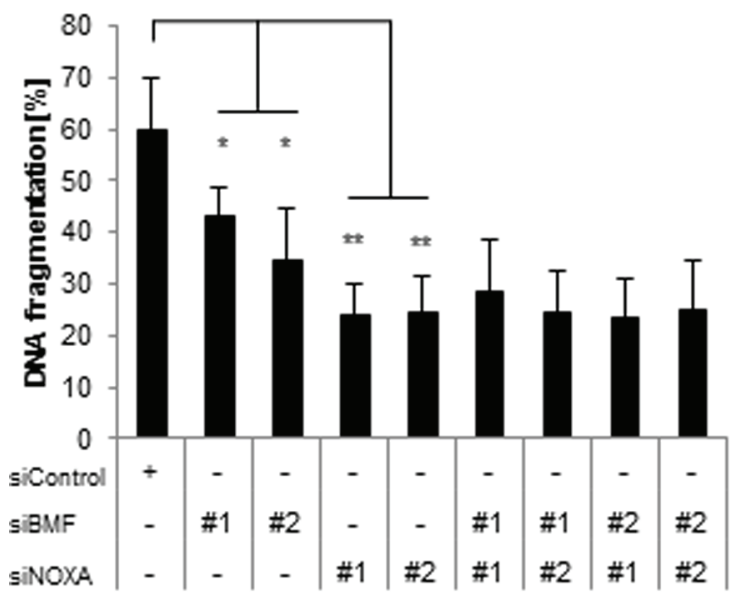

RMS13

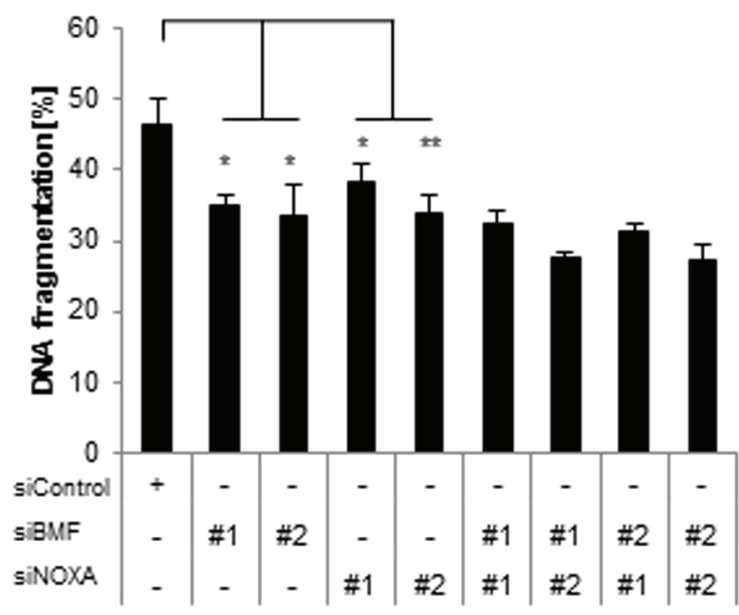

VJ

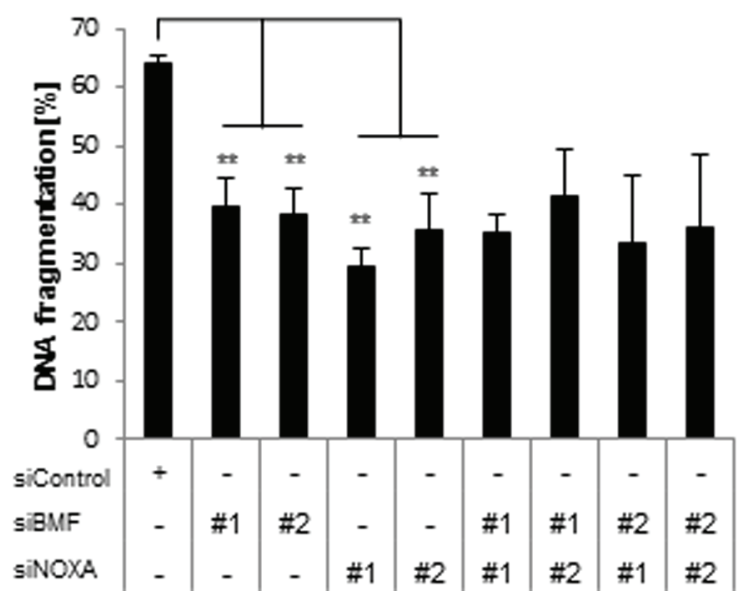

TE381.T

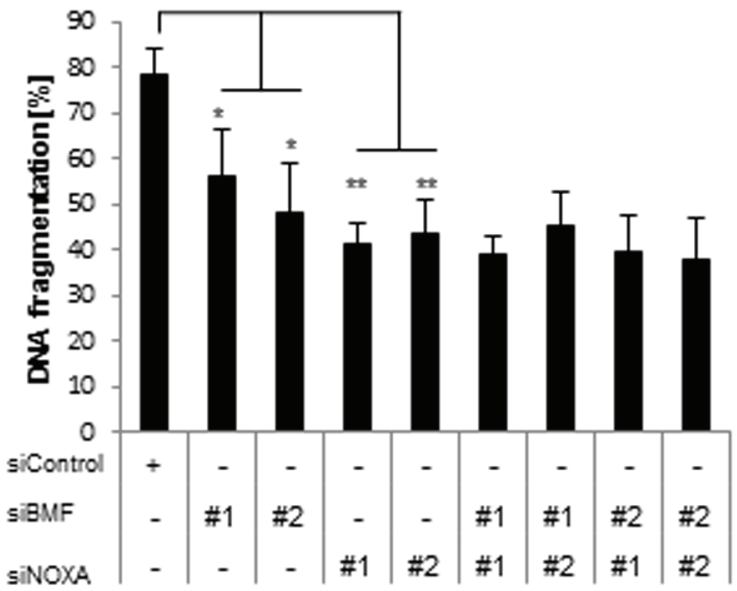

RH30

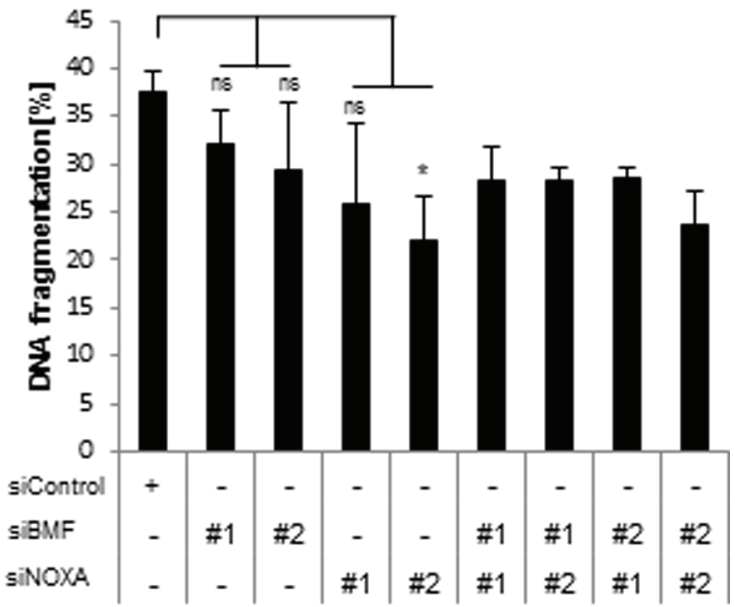

Figure 4: NOXA and BMF are required for GANT61/PI103-induced apoptosis. RD, TE381.T, RMS13, RH30 and VJ cells were transfected with non-silencing siRNA (siControl) or siRNA targeting BMF and/or NOXA and treated for 48 hours with PI103 $(1 \mu \mathrm{M})$ and GANT61 (RD $6 \mu \mathrm{M}$; TE381.T $8 \mu \mathrm{M}$; RMS13 $10 \mu \mathrm{M}$; RH30 $8 \mu \mathrm{M}$; VJ $8 \mu \mathrm{M}$ ). Apoptosis was determined by DNA fragmentation of PI-stained nuclei using flow cytometry. Mean + S.D. of at least three independent experiments performed in triplicate are shown; ${ }^{*} p<0.05$; ** $p<0.01$. Statistic analysis comparing combined knockdown to single knockdown is shown in Suppl. Table 2. 

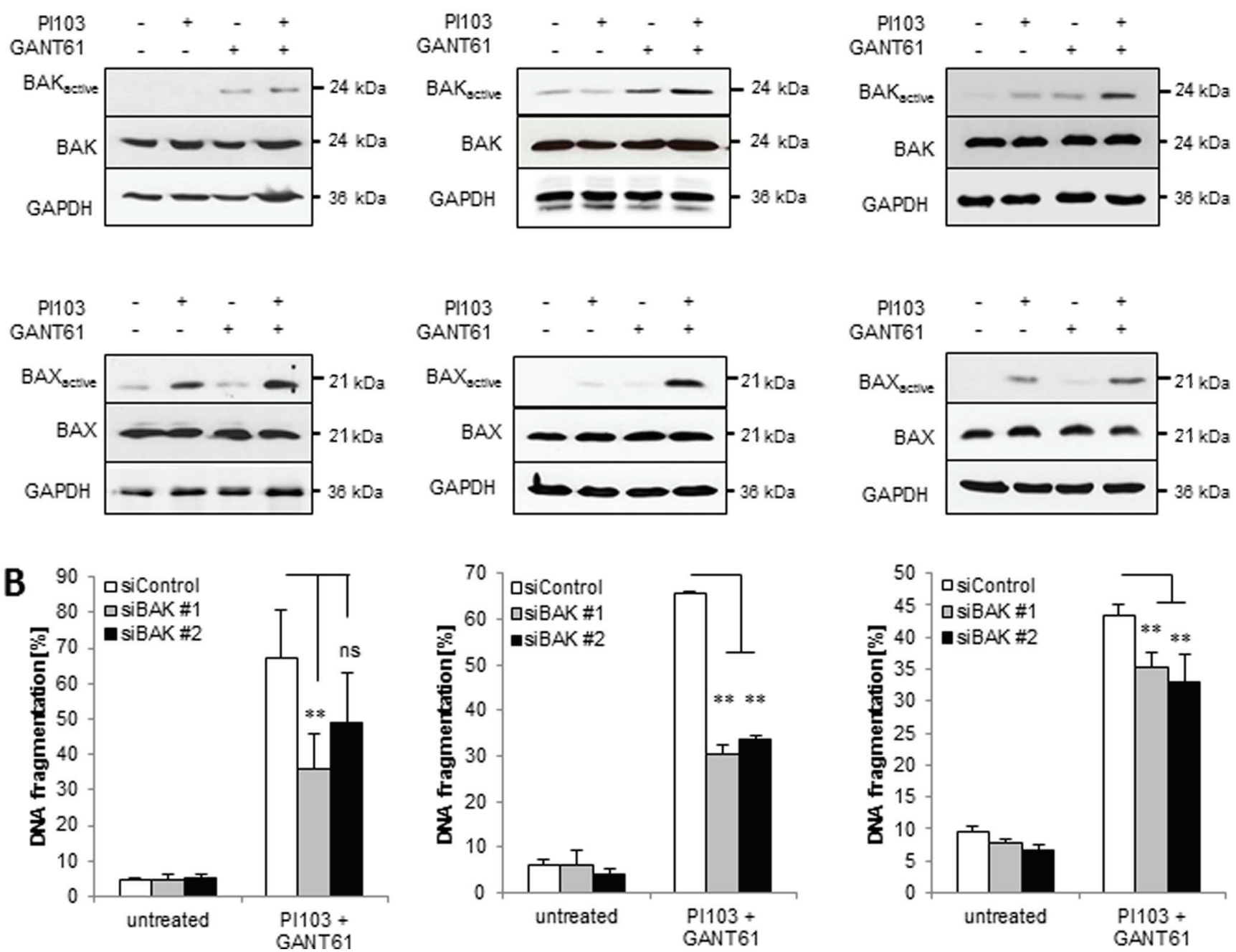

Figure 5: GANT61/PI103-mediated BAX/BAK activation is required for apoptosis. (A) RD, TE381.T and RH30 cells were treated with $1 \mu \mathrm{M}$ PI103 and/or GANT61 (RD $6 \mu \mathrm{M}$; TE381.T $8 \mu \mathrm{M}$; RH30 $8 \mu \mathrm{M}$ ) and activation of BAK and BAX was determined after 24 hours by immunoprecipitation using active conformation-specific antibodies; representative blots are shown. (B) cells were transfected with non-silencing siRNA (siControl) or siRNA targeting BAK, treated with $1 \mu \mathrm{M}$ PI103 and GANT61 (RD $6 \mu \mathrm{M}$; TE381.T $8 \mu \mathrm{M}$; RH30 $8 \mu \mathrm{M}$ ) for 48 hours and apoptosis was determined by DNA fragmentation of PI-stained nuclei using flow cytometry. Mean + S.D. of three independent experiments performed in triplicate are shown; ${ }^{*} p<0.05 ;{ }^{*} p<0.01$; ns: not significant.

evidence showing that the $\mathrm{HH}$ pathway is not only activated via canonical signaling, but also in a noncanonical manner, which may lead to resistance against SMO inhibitors [27]. Therefore, we targeted $\mathrm{HH}$ signaling at different levels alone or in combination with inhibition of $\mathrm{HH}$-interacting pathways.

In this study, we identify a synthetic lethal interaction of concomitant inhibition of $\mathrm{HH}$ and $\mathrm{PI} 3 \mathrm{~K} /$ AKT/mTOR pathways in RMS. The combination of the GLI1/2 inhibitor GANT61 and PI3K/mTOR inhibitor PI103 is highly synergistic at subtoxic concentrations of both inhibitors as underscored by calculation of CI values $(\mathrm{CI}<0.2)$. Similarly, genetic silencing of GLI1 and GLI2 cooperates with PI103 to induce apoptosis. The clinical relevance of this combination is emphasized by experiments using a patient-derived primary tumor sample, which similarly demonstrates the synergistic interaction of GANT61/PI103 cotreatment. The potency of this combination therapy is underlined by our data showing that GANT61/PI103 cotreatment reduces clonogenic survival, suppresses 3D rhabdosphere formation and, most importantly, inhibits tumor growth in an in vivo model of RMS. Based on these findings, we conclude that combined GLI1/2 and PI3K/mTOR inhibition is a promising novel therapeutic approach for synergistic apoptosis induction and tumor growth reduction in RMS. 
A

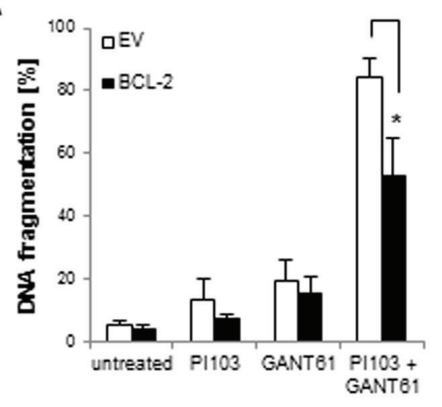

B

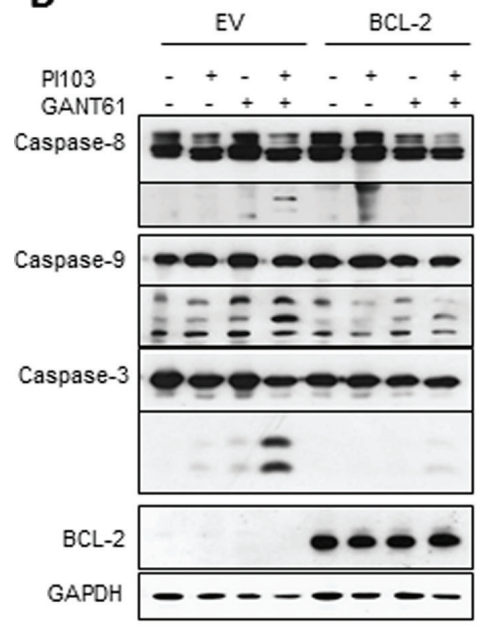

C

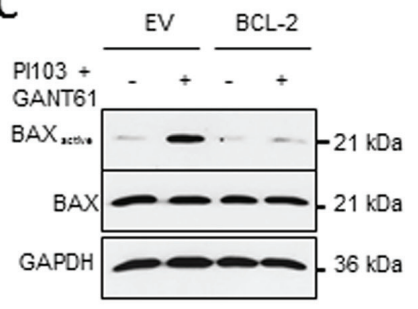

TE381.T
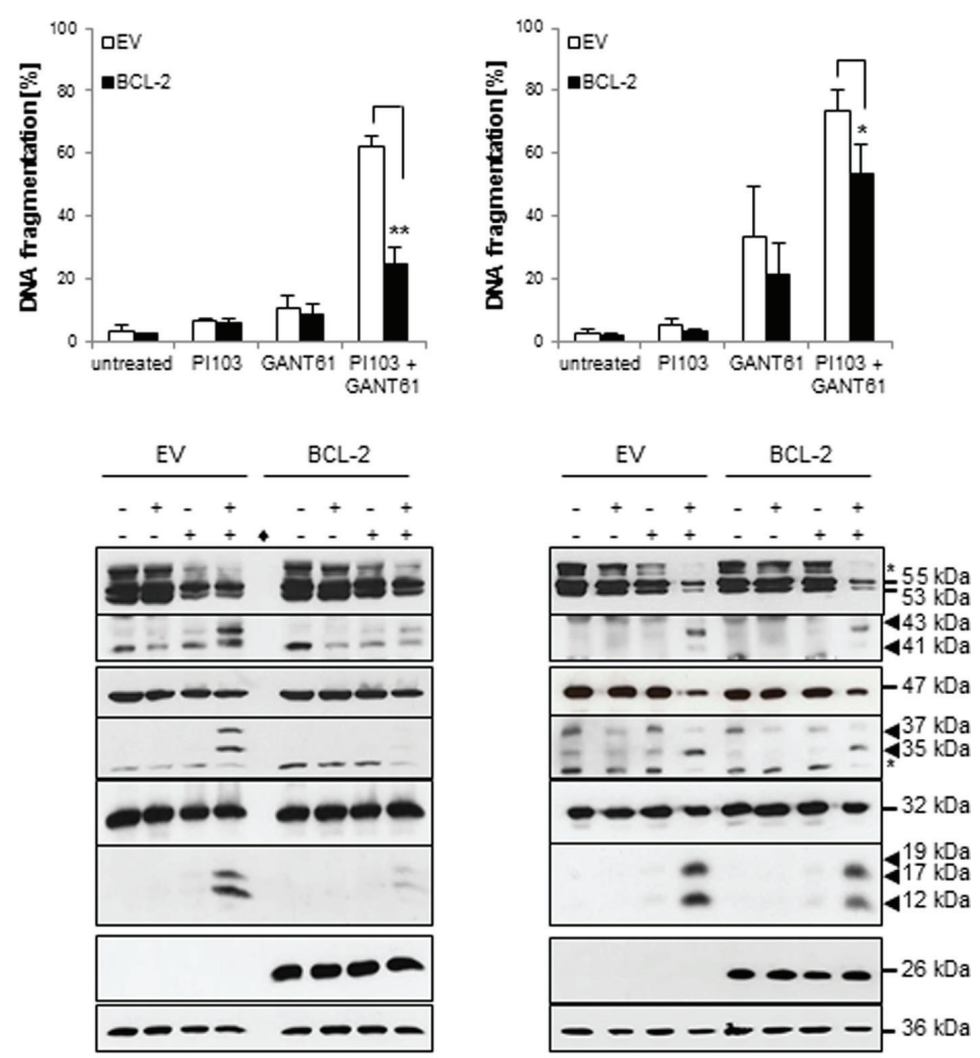

D
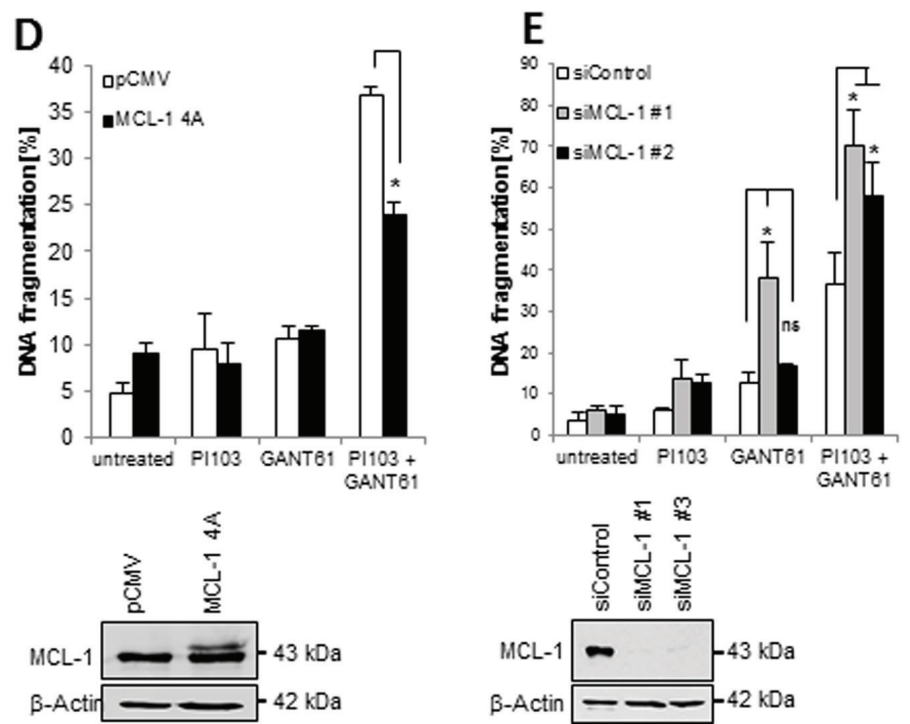

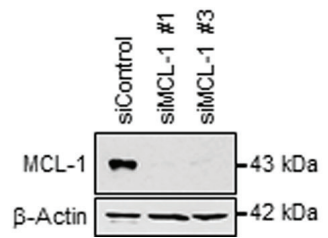

Figure 6: Overexpression of BCL-2 and phospho-mutant MCL-1 rescue GANT61/PI103-induced apoptosis. (A-C), RD, TE381.T and RH30 cells were transfected with a murine BCL-2 construct or empty vector and treated with $1 \mu \mathrm{M}$ PI103 and GANT61 (RD $6 \mu \mathrm{M}$; TE381.T $8 \mu \mathrm{M}$; RH30 $8 \mu \mathrm{M}$ ). A, apoptosis was determined after 48 hours by DNA fragmentation of PI-stained nuclei using flow cytometry. B, caspase activation was determined by Western blotting after 24 hours; arrow heads indicate cleavage fragments; asterisks indicate unspecific bands; diamond indicates empty lane. C, BAX activation was determined after 24 hours by immunoprecipitation using active conformation-specific antibodies. (D) RD cells were transfected with a non-degradable phospho-mutant MCL-1 construct or empty vector, treated with $1 \mu \mathrm{M}$ PI103 and $6 \mu \mathrm{M}$ GANT61 and apoptosis was determined after 48 hours by DNA fragmentation of PI-stained nuclei using flow cytometry (upper panel). Overexpression of the MCL-1 construct was verified by Western blotting (lower panel). (E) RD cells were transfected with non-silencing siRNA (siControl) or two different siRNAs targeting MCL-1 and apoptosis was determined after 48 hours by DNA fragmentation of PI-stained nuclei using flow cytometry (upper panel). MCL-1 knockdown was verified by Western blotting (lower panel). Mean + S.D. of three independent experiments performed in triplicate (A, D, E) or representative blots (B-E) are shown; ${ }^{*} p<0.05 ; * * p<0.01$; ns: not significant. 
A
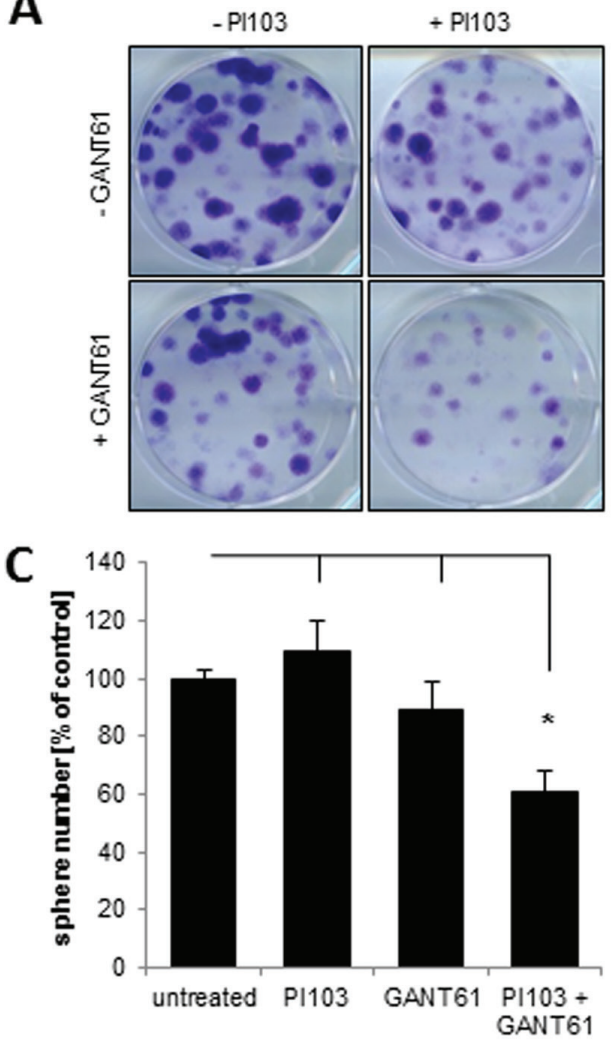

E

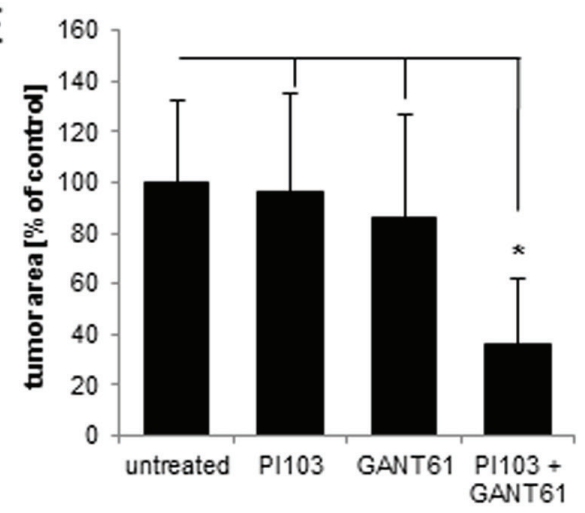

B

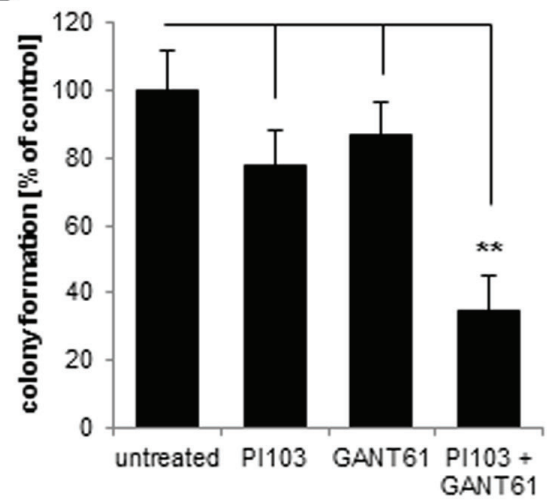

D

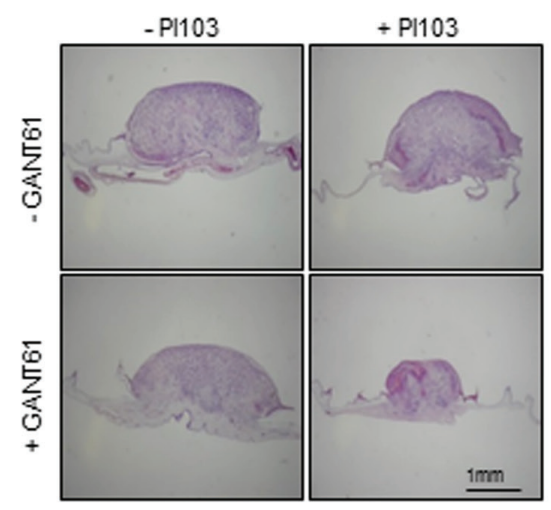

$\mathbf{F}$

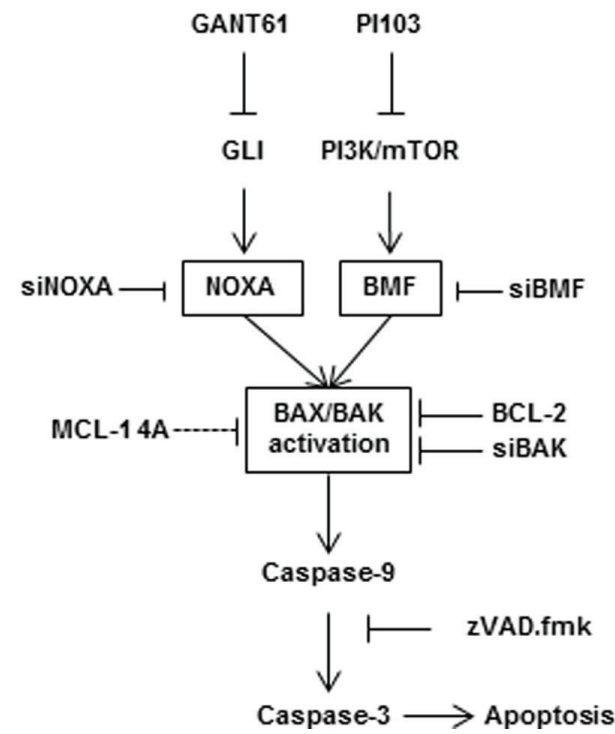

Figure 7: GANT61 and PI103 cooperate to suppress clonogenic survival, 3D sphere formation and tumor growth in vivo. (A and B) RD cells were treated for 18 hours with $1 \mu \mathrm{M}$ PI103 and/or $6 \mu \mathrm{M}$ GANT61 and clonogenic survival was assessed by colony formation assay at day 10 . Representative images are shown (A); the number of colonies was counted after crystal violet staining and is expressed as percentage of untreated controls (B) (C) RD cells were treated for 24 hours with $1 \mu \mathrm{M}$ PI103 and/or $6 \mu \mathrm{M}$ and spheres were counted after 15 days. (D and E), RD cells were seeded on the CAM of fertilized chicken eggs, treated with $2 \mu \mathrm{M}$ PI103 and/or $20 \mu \mathrm{M}$ GANT61 for three days and tumor growth was analyzed using H/E-stained paraffin sections of the CAM. Representative pictures of at least 15 tumors (D) and quantification of tumor area (E) are shown. Mean + S.D. of three independent experiments performed at least in triplicate are shown (B, C, E); ${ }^{*} p<0.05 ;{ }^{* *} p<0.01$. (F) Scheme of the proposed mechanism of GANT61/PI103 induced mitochondrial apoptosis. GANT61 and PI103 treatment results in NOXA and BMF upregulation and subsequently BAX and BAK activation. BAX/BAK activation leads to cleavage of caspase-9 and activation of caspase-3 as execution pathway of apoptosis. GANT61/PI103-induced apoptosis is inhibited by overexpression of BCL-2 or phospho-mutant MCL-1, by knockdown of NOXA, BMF or BAK or by caspase inhibitor zVAD.fmk. 
Mechanistic studies revealed that the synergistic interaction of GANT61/PI103 cotreatment is mediated by the mitochondrial pathway of apoptosis via upregulation of the proapoptotic proteins NOXA and BMF, followed by activation of BAX and BAK and subsequent cleavage of caspases, as demonstrated by several lines of evidence (Fig. 7F).

First, single treatment with either inhibitor alone leads to upregulation of different proapoptotic BH3-only proteins, which is further increased after combination treatment. PI103 single treatment upregulates BMF, while GANT61 single treatment increases NOXA levels. PI3K/ AKT/mTOR inhibition has been shown to repress CAPdependent protein translation resulting in a shift towards internal ribosome entry site (IRES)-mediated translation and upregulation of BMF [28]. Also, it is interesting to note that arsenic trioxide, which can decrease GLI1 and GLI2 levels [29, 30], has been reported to increase NOXA mRNA and protein expression [31]. This emphasizes that $\mathrm{HH}$ inhibition can lead to upregulation of NOXA. Our findings showing that knockdown of NOXA or BMF attenuates GANT61/PI103-induced apoptosis highlight the functional relevance and non-redundant functions of these BH3-only proteins during GANT61/PI103-mediated apoptosis. The notion that signaling via the mitochondrial pathway is required for the synergistic induction of apoptosis is underscored by rescue experiments showing that inhibition of the mitochondrial pathway by overexpression of BCL-2, by ectopic expression of a nondegradable MCL-1 mutant or by BAK silencing provides protection against GANT61/PI103-induced apoptosis.

Second, GANT61 and PI103 cooperate to trigger caspase activation via the mitochondrial pathway of apoptosis, as indicated by changes in the cleavage pattern of caspases upon addition of the broad-range caspase inhibitor zVAD.fmk. Accordingly, accumulation of the caspase-9 p35 cleavage fragment upon addition of zVAD. fmk to GANT61/PI103-treated cells is consistent with cleavage of the initiator caspase- 9 via induced proximity within the apoptosome, an event that does not require caspase activity and therefore is not inhibited by zVAD. fmk [32]. By comparison, reduced generation of the p37 cleavage fragment of caspase-9 upon GANT61/PI103 co-treatment in the presence of zVAD.fmk is in line with the notion that caspase- 3 cleaves caspase- 9 into the 37$\mathrm{kDa}$ fragment in a feedback amplification loop [33]. Accumulation of the 19-kDa fragment of caspase-3 in GANT61/PI103-treated cells in the presence of zVAD.fmk is consistent with increased caspase-9 activity, whereas subsequent autoproteolytic processing of caspase- 3 into the $12-$ and $17-\mathrm{kDa}$ fragments is inhibited by zVAD. fmk [34]. Slight activation of caspase-8 upon GANT61/ PI103 cotreatment is likely caused by one of the effector caspases such as caspase- 3 , as it is blocked by zVAD. fmk. Caspase- 8 may initiate a feedback amplification loop, for example by cleaving BID into tBID, which further enhances GANT61/PI103-induced apoptosis. Together, these mechanistic studies underscore that the mitochondrial pathway plays a critical role in mediating GANT61/PI103-induced apoptosis.

Canonical as well as non-canonical mechanisms can cause aberrant HH pathway activation in RMS. Inherited mutations in $P T C H$ can give rise to RMS in both humans and mice, and human sporadic RMS samples were reported to harbor mutations in $P T C H$ or $S U F U$ as well as amplification of GLI1 and GLI2 loci [24, 35-40]. Furthermore, RMS often exhibit active PI3K/AKT/mTOR signaling [41] that contributes to non-canonical $\mathrm{HH}$ activation via phosphorylation of GLI1, which potentiates its transcriptional activity [13]. In line with non-canonical HH activation in RMS, our study reveals that concomitant inhibition of GLI and PI3K/mTOR signaling is required to induce apoptosis in RMS cells. Consistently, GANT61/ PI103 cotreatment leads to profound and sustained suppression of both $\mathrm{HH}$ and PI3K/AKT/mTOR signaling compared to either treatment alone, highlighting the crosstalk of these pathways downstream of SMO. By comparison, we demonstrate that treatment with the SMO inhibitor GDC-0449 alone or in combination with PI3K/ mTOR inhibition fails to induce apoptosis in RMS cells. As far as the RMS cell lines used in the present study are concerned, RH30 and RMS13 cells have been described to harbor GLI1 amplification [23, 24]. Also, inhibition of GLI has previously been reported to be more efficient in RMS cell lines than inhibition of SMO by cyclopamine or by genetic silencing [42].

While tumors with documented $\mathrm{HH}$ activation caused by $\mathrm{LOH}$ of $\mathrm{PTCH}$ such as BCC have been described to respond to SMO inhibitors [43], there is mounting evidence showing that these inhibitors exhibit limited efficiency against tumors with non-canonical $\mathrm{HH}$ activation, e.g. due to mutations downstream of SMO, GLI amplification or activation of HH-interacting pathways such as the PI3K/ AKT/mTOR cascade $[13,16,44,45]$. In glioblastoma harboring PI3K/mTOR activation due to PTEN deficiency, combined inhibition using the SMO inhibitor LDE225 and the PI3K inhibitor BKM120 was necessary to reduce cell viability and inhibit tumor growth [12]. Likewise, cotreatment with the SMO inhibitor GDC-0449 and the mTOR inhibitor RAD001 suppressed tumor growth of esophageal cancer in vivo [13]. These studies highlight the need of concomitant inhibition of HH and PI3K/AKT/ mTOR pathways in tumors with non-canonical $\mathrm{HH}$ pathway activation. This approach is currently under evaluation in clinical trials in pancreatic cancer (i.e. GDC-0449 and Rapamycin) and in advanced solid tumors (i.e. LDE225 and BKM120) [45].

Co-targeting of $\mathrm{HH}$ and PI3K/AKT/mTOR pathways not only provides a promising strategy to bypass primary resistance to SMO inhibitors due to non-canonical $\mathrm{HH}$ activation, but also to overcome secondary resistance to these inhibitors. The development of resistance has 
been documented upon monotherapy with SMO inhibitors both in humans and mice, e.g. due to acquired mutations in SMO, GLI2 amplification or $\mathrm{PI} 3 \mathrm{~K} / \mathrm{AKT} / \mathrm{mTOR}$ activation [27, 46, 47]. For example in a mouse model of medulloblastoma, addition of PI3K inhibitor BKM120 or $\mathrm{PI} 3 \mathrm{~K} / \mathrm{mTOR}$ inhibitor BEZ235 to the initial treatment with SMO inhibitor LDE225 markedly delayed the occurrence of resistance [47].

Our study has important implications for the development of $\mathrm{HH}$ pathway-targeted therapies in RMS. The identification of synthetic lethality by combined inhibition of $\mathrm{HH}$ signaling at the level of GLI and of $\mathrm{PI} 3 \mathrm{~K} / \mathrm{mTOR}$ in the present study is relevant for RMS, since non-canonical mechanisms contribute to aberrant $\mathrm{HH}$ pathway activation. Beyond RMS, our results are also of broader relevance for other $\mathrm{HH}$-driven cancer with non-canonical $\mathrm{HH}$ activation. One future challenge is the development of clinically applicable GLI-targeting drugs. Here, inhibition of bromo and extra C-terminal (BET) bromodomain proteins may open new perspectives, as the small-molecule BET bromodomain inhibitor JQ1 has recently been reported to block GLI transcriptional output downstream of SMO [48]. Taken together, HH pathwaytargeted therapies may open new perspectives for more effective treatment options for RMS.

\section{METHODS}

\section{Cell culture and chemicals}

RMS cell lines were obtained from the American Type Culture Collection (Manassas, VA, USA) and maintained in RPMI 1640 or DMEM medium (Life Technologies., Eggenstein, Germany), supplemented with $10 \%$ fetal calf serum (FCS) (Biochrom, Berlin, Germany), 1 mM glutamine and $1 \%$ penicillin/streptomycin (Invitrogen, Karlsruhe, Germany). VJ cells were generated from a primary cultured RMS derived from a patient diagnozed with RMS (histologically confirmed alveolar rhabdomyosarcoma) and cultured in DMEM medium. zVAD.fmk was purchased from Bachem (Heidelberg, Germany). GDC-0449 [49] and GDC0941 were kindly provided by Genetech Inc. (South San Francisco, CA, USA), PI3K/mTOR inhibitor PI103 [50] was purchased from Merck Millipore (Darmstadt, Germany) and GLI1/2 inhibitor GANT61 [51] from Sigma (Deisenhofen, Germany). BEZ235 and RAD001 were kindly provided by Novartis Institute for BioMedical Research (Oncology Basel, Novartis Pharma AG, Basel Switzerland). AZD8055 was obtained from Selleck Chemicals (Houston, Texas). All chemicals were purchased from Sigma unless indicated otherwise.

\section{Determination of apoptosis and cell viability}

Apoptosis was determined by analysis of DNA fragmentation of propidium iodide (PI)-stained nuclei using flow cytometry (FACSCanto II, BD Biosciences, Heidelberg, Germany) as described previously [52]. Cell viability was assessed by 3-(4,5-dimethylthiazol-2-yl)2,5-diphenyltetrazolium bromide (MTT) assay according to the manufacturer's instructions (Roche Diagnostics, Mannheim, Germany).

\section{Determination of colony formation and sphere formation}

For colony assay, cells were treated for 18 hours, re-seeded as single cells (200 cells/well) in six-well plates and cultured for additional 10 days before colonies were stained with crystal violet (Roth, Karlsruhe, Germany) and counted. For sphere formation, cells were treated for 24 hours and seeded as single cells in stem cell culture medium in ultra low attachment plates as previously described [53].

\section{Western blot analysis}

Western blot analysis was performed as described previously [52] using the following antibodies: mouse anti-caspase-8, mouse anti-NOXA, rat anti-BMF (Alexis Biochemicals, Grünberg, Germany), mouse anti-AKT, mouse anti-BCL-2, mouse anti-BAX, rabbit anti-BAK (BD Bioscience), rabbit anti-caspase-3, mouse anticaspase-9, rabbit anti-pAKT, rabbit anti-p4E-BP1, rabbit anti-4E-BP1, rabbit anti-pS6, mouse anti-S6, (Cell Signaling, Beverly, MA), rabbit anti-MCL-1 (Stressgene Bioreagents, Victoria, BC). Mouse anti-GAPDH (HyTest, Turku, Finland) or mouse anti- $\beta$-Actin (Sigma) were used as loading controls. Goat anti-mouse IgG, donkey antigoat $\mathrm{IgG}$, goat anti-rabbit IgG conjugated to horseradish peroxidase (Santa Cruz Biotechnology, Santa Cruz, CA)) and goat anti-mouse IgG1 or goat anti-mouse IgG2b (Southern Biotech, Birmingham, AL) conjugated to horseradish peroxidase were used as secondary antibodies. Enhanced chemiluminescence was used for detection (Amersham Bioscience, Freiburg, Germany). Representative blots of at least two independent experiments are shown.

\section{BAX/BAK activation}

A total of $1000 \mu \mathrm{g}$ protein was immunoprecipitated with mouse anti-BAX antibody (6A7, Sigma) or mouse anti-BAK (TC-100, Merck Millipore) and $5 \mu$ Dynabeads Pan Mouse IgG (Dako, Hamburg, Germany). The precipitate was analyzed by Western blotting using the BAX NT antibody (Merck Millipore) or BAK antibody (BD, Bioscience).

\section{Statistical analysis}

Statistical significance was assessed by Student's $t$-Test (two-tailed distribution, two-sample, unequal 
variance). Interaction between PI103 and GANT61 was analyzed by the Combination index (CI) method based on that described by [54] using CalcuSyn software (Biosoft, Cambridge, UK). CI $<0.9$ indicates synergism, 0.9-1.1 additivity and $>1.1$ antagonism.

\section{Transient RNA interference}

For transient knockdown by siRNA, cells were reversely transfected with $10 \mathrm{nM}$ SilencerSelect siRNA (Invitrogen), control siRNA (4390843) or targeting siRNAs (s8583 and s8585 for MCL-1; s40385 and s40386 for BMF, s10708 and s10709 for NOXA, s5814 for GLI1, s5817 for GLI2, s1880 and s1881 for BAK) using Lipofectamine RNAi Max (Invitrogen) and OptiMEM (Life Technologies).

\section{Transduction}

For BCL-2 overexpression, cells were transduced with murine stem cell virus (pMSCV, Clontech, Mountain View, CA) vector containing mouse BCL-2 or empty vector using the packaging cell line 293T (BD Biosciences). Stable cell lines were selected with $10 \mu \mathrm{g} /$ ml Blasticidin (Invitrogen). For phospho-mutant MCL-1, cells were transduced with a pCMV vector containing 4A (S64A/S121A/S159A/T163A) and empty vector by Genentech (South San Francisco) and were selected with Neomycin (Roth).

\section{CAM assay}

CAM assay was done as described previously [26]. Briefly, $10^{6}$ cells were implanted on fertilized chicken eggs on day eight of incubation, treated with $2 \mu \mathrm{M}$ PI103 and $20 \mu \mathrm{M}$ GANT61 for three days, sampled with the surrounding CAM, fixed in 4\% paraformaldehyde, paraffin embedded, cut in 5-mm sections and were analyzed by immunohistochemistry using 1:1 hematoxylin and $0.5 \%$ eosin $(\mathrm{H} / \mathrm{E})$. Images were digitally recorded using an AX70 microscope (Olympus, Center Valley, PA, USA) and tumor areas were analyzed by Image J digital imaging software (NIH, Bethesda, MA, USA).

\section{Quantitative real-time PCR}

Total RNA was extracted using peqGOLD Total RNA kit from Peqlab Biotechnologie $\mathrm{GmbH}$ (Erlangen, Germany) according to the manufacturer's instructions. Total RNA ( $2 \mu \mathrm{g})$ was used to synthesize the corresponding cDNA using RevertAid H Minus First Strand cDNA Synthesis Kit (MBI Fermentas GmbH, St. Leon-Rot, Germany). To quantify gene expression levels, SYBRGreen based quantitative RT-qPCR was performed using the $7900 \mathrm{HT}$ fast real-time PCR system from Applied Biosystems (Darmstadt, Germany). Data were normalized on 28S-rRNA expression as reference gene.
Primers are listed in Suppl. Table S3. Melting curves were plotted to verify the specificity of the amplified products. The relative expression of the target gene transcript and reference gene transcript was calculated as $\Delta \Delta \mathrm{c}_{\mathrm{t}}$. At least two independent experiments were performed for each gene.

\section{ACKNOWLEDGMENTS}

We thank T. Klingebiel and S. Wehner for providing the RMS sample, D. Brücher for expert technical assistance, and C. Hugenberg for expert secretarial assistance. This work has been partially supported by grants from the Deutsche Krebshilfe and BMBF (to S.F.).

\section{CONFLICT OF INTEREST}

The authors declare no conflict of interest.

\section{REFERENCES}

1. Gallego Melcon S, Sanchez de Toledo Codina J. Molecular biology of rhabdomyosarcoma. Clin Transl Oncol. 2007; 9:415-419.

2. Parham DM, Barr FG. Classification of rhabdomyosarcoma and its molecular basis. Adv Anat Pathol. 2013; 20:387-397.

3. Bridge JA, Liu J, Weibolt V, Baker KS, Perry D, Kruger R, Qualman S, Barr F, Sorensen P, Triche T, Suijkerbuijk R. Novel genomic imbalances in embryonal rhabdomyosarcoma revealed by comparative genomic hybridization and fluorescence in situ hybridization: an intergroup rhabdomyosarcoma study. Genes Chromosomes Cancer. 2000; 27:337-344.

4. Gorlin RJ. Nevoid basal cell carcinoma syndrome. Dermatol Clin. 1995; 13:113-125.

5. Hahn H, Wicking C, Zaphiropoulous PG, Gailani MR, Shanley S, Chidambaram A, Vorechovsky I, Holmberg E, Unden AB, Gillies S, Negus K, Smyth I, Pressman C, et al. Mutations of the human homolog of Drosophila patched in the nevoid basal cell carcinoma syndrome. Cell. 1996; 85:841-851.

6. Johnson RL, Rothman AL, Xie J, Goodrich LV, Bare JW, Bonifas JM, Quinn AG, Myers RM, Cox DR, Epstein EH Jr., Scott MP. Human homolog of patched, a candidate gene for the basal cell nevus syndrome. Science. 1996; 272:1668-1671.

7. Hahn H, Wojnowski L, Zimmer AM, Hall J, Miller G, Zimmer A. Rhabdomyosarcomas and radiation hypersensitivity in a mouse model of Gorlin syndrome. Nat Med. 1998; 4:619-622.

8. Ryan KE, Chiang C. Hedgehog secretion and signal transduction in vertebrates. J Biol Chem. 2012; 287:17905-17913.

9. Eichberger $T$, Sander V, Schnidar H, Regl G, Kasper M, Schmid C, Plamberger S, Kaser A, 
Aberger F, Frischauf AM. Overlapping and distinct transcriptional regulator properties of the GLI1 and GLI2 oncogenes. Genomics. 2006; 87:616-632.

10. Varjosalo M, Taipale J. Hedgehog: functions and mechanisms. Genes Dev. 2008; 22:2454-2472.

11. Stecca B, Mas C, Clement V, Zbinden M, Correa R, Piguet V, Beermann F, Ruiz IAA. Melanomas require HEDGEHOG-GLI signaling regulated by interactions between GLI1 and the RAS-MEK/AKT pathways. Proc Natl Acad Sci U S A. 2007; 104:5895-5900.

12. Gruber Filbin M, Dabral SK, Pazyra-Murphy MF, Ramkissoon S, Kung AL, Pak E, Chung J, Theisen MA, Sun Y, Franchetti Y, Sun Y, Shulman DS, Redjal N, et al. Coordinate activation of Shh and PI3K signaling in PTENdeficient glioblastoma: new therapeutic opportunities. Nat Med. 2013; 19:1518-1523.

13. Wang Y, Ding Q, Yen CJ, Xia W, Izzo JG, Lang JY, Li CW, Hsu JL, Miller SA, Wang X, Lee DF, Hsu JM, Huo L, et al. The crosstalk of mTOR/S6K1 and Hedgehog pathways. Cancer Cell. 2012; 21:374-387.

14. Nolan-Stevaux O, Lau J, Truitt ML, Chu GC, Hebrok M, Fernandez-Zapico ME, Hanahan D. GLI1 is regulated through Smoothened-independent mechanisms in neoplastic pancreatic ducts and mediates PDAC cell survival and transformation. Genes Dev. 2009; 23:24-36.

15. Seto $M$, Ohta $M$, Asaoka $Y$, Ikenoue $T$, Tada $M$, Miyabayashi K, Mohri D, Tanaka Y, Ijichi H, Tateishi K, Kanai F, Kawabe T, Omata M. Regulation of the hedgehog signaling by the mitogen-activated protein kinase cascade in gastric cancer. Mol Carcinog. 2009; 48:703-712.

16. Wei L, Xu Z. Cross-signaling among phosphinositide-3 kinase, mitogen-activated protein kinase and sonic hedgehog pathways exists in esophageal cancer. Int J Cancer. 2011; 129:275-284.

17. Ramaswamy B, Lu Y, Teng KY, Nuovo G, Li X, Shapiro $\mathrm{CL}$, Majumder S. Hedgehog signaling is a novel therapeutic target in tamoxifen-resistant breast cancer aberrantly activated by PI3K/AKT pathway. Cancer Res. 2012; 72:5048-5059.

18. Fulda S. Tumor resistance to apoptosis. Int J Cancer. 2009; 124:511-515.

19. Fulda S, Debatin KM. Extrinsic versus intrinsic apoptosis pathways in anticancer chemotherapy. Oncogene. 2006; 25:4798-4811.

20. Adams JM, Cory S. Bcl-2-regulated apoptosis: mechanism and therapeutic potential. Curr Opin Immunol. 2007; 19:488-496.

21. Riedl SJ, Salvesen GS. The apoptosome: signalling platform of cell death. Nat Rev Mol Cell Biol. 2007; 8:405-413.

22. Zibat A, Missiaglia E, Rosenberger A, Pritchard-Jones K, Shipley J, Hahn H, Fulda S. Activation of the hedgehog pathway confers a poor prognosis in embryonal and fusion gene-negative alveolar rhabdomyosarcoma. Oncogene. 2010; 29:6323-6330.
23. Roberts WM, Douglass EC, Peiper SC, Houghton PJ, Look AT. Amplification of the gli gene in childhood sarcomas. Cancer Res. 1989; 49:5407-5413.

24. Bridge JA, Liu J, Qualman SJ, Suijkerbuijk R, Wenger G, Zhang J, Wan X, Baker KS, Sorensen P, Barr FG. Genomic gains and losses are similar in genetic and histologic subsets of rhabdomyosarcoma, whereas amplification predominates in embryonal with anaplasia and alveolar subtypes. Genes Chromosomes Cancer. 2002; 33:310-321.

25. Wertz IE, Kusam S, Lam C, Okamoto T, Sandoval W, Anderson DJ, Helgason E, Ernst JA, Eby M, Liu J, Belmont LD, Kaminker JS, O'Rourke KM, et al. Sensitivity to antitubulin chemotherapeutics is regulated by MCL1 and FBW7. Nature. 2011; 471:110-114.

26. Hacker S, Dittrich A, Mohr A, Schweitzer T, Rutkowski S, Krauss J, Debatin KM, Fulda S. Histone deacetylase inhibitors cooperate with IFN-gamma to restore caspase- 8 expression and overcome TRAIL resistance in cancers with silencing of caspase-8. Oncogene. 2009; 28:3097-3110.

27. Yauch RL, Dijkgraaf GJ, Alicke B, Januario T, Ahn CP, Holcomb T, Pujara K, Stinson J, Callahan CA, Tang T, Bazan JF, Kan Z, Seshagiri S, et al. Smoothened mutation confers resistance to a Hedgehog pathway inhibitor in medulloblastoma. Science. 2009; 326:572-574.

28. Grespi F, Soratroi C, Krumschnabel G, Sohm B, Ploner C, Geley S, Hengst L, Hacker G, Villunger A. BH3-only protein Bmf mediates apoptosis upon inhibition of CAPdependent protein synthesis. Cell Death Differ. 2010; 17:1672-1683.

29. Beauchamp EM, Ringer L, Bulut G, Sajwan KP, Hall MD, Lee YC, Peaceman D, Ozdemirli M, Rodriguez O, Macdonald TJ, Albanese C, Toretsky JA, Uren A. Arsenic trioxide inhibits human cancer cell growth and tumor development in mice by blocking Hedgehog/GLI pathway. J Clin Invest. $2011 ; 121: 148-160$.

30. Kim J, Lee JJ, Kim J, Gardner D, Beachy PA. Arsenic antagonizes the Hedgehog pathway by preventing ciliary accumulation and reducing stability of the Gli2 transcriptional effector. Proc Natl Acad Sci U S A. 2010; 107:13432-13437.

31. Morales AA, Gutman D, Lee KP, Boise LH. BH3-only proteins Noxa, Bmf, and Bim are necessary for arsenic trioxide-induced cell death in myeloma. Blood. 2008; 111:5152-5162.

32. Cain K, Bratton SB, Cohen GM. The Apaf-1 apoptosome: a large caspase-activating complex. Biochimie. 2002; 84:203-214.

33. Zou H, Yang R, Hao J, Wang J, Sun C, Fesik SW, Wu JC, Tomaselli KJ, Armstrong RC. Regulation of the Apaf-1/ caspase-9 apoptosome by caspase-3 and XIAP. J Biol Chem. 2003; 278:8091-8098.

34. Han Z, Hendrickson EA, Bremner TA, Wyche JH. A sequential two-step mechanism for the production of the 
mature p17:p12 form of caspase-3 in vitro. J Biol Chem. 1997; 272:13432-13436.

35. Tostar U, Malm CJ, Meis-Kindblom JM, Kindblom LG, Toftgard R, Unden AB. Deregulation of the hedgehog signalling pathway: a possible role for the PTCH and SUFU genes in human rhabdomyoma and rhabdomyosarcoma development. J Pathol. 2006; 208:17-25.

36. Calzada-Wack J, Schnitzbauer U, Walch A, Wurster KH, Kappler R, Nathrath M, Hahn H. Analysis of the PTCH coding region in human rhabdomyosarcoma. Hum Mutat. 2002; 20:233-234.

37. Ragazzini P, Gamberi G, Pazzaglia L, Serra M, Magagnoli G, Ponticelli F, Ferrari C, Ghinelli C, Alberghini M, Bertoni F, Picci P, Benassi MS. Amplification of CDK4, MDM2, SAS and GLI genes in leiomyosarcoma, alveolar and embryonal rhabdomyosarcoma. Histol Histopathol. 2004; 19:401-411.

38. Pressey JG, Anderson JR, Crossman DK, Lynch JC, Barr FG. Hedgehog pathway activity in pediatric embryonal rhabdomyosarcoma and undifferentiated sarcoma: a report from the Children's Oncology Group. Pediatr Blood Cancer. 2011; 57:930-938.

39. Roberts WM, Douglass EC, Peiper SC, Houghton PJ, Look AT. Amplification of the gli gene in childhood sarcomas. Cancer Res. 1989; 49:5407-5413.

40. Paulson V, Chandler G, Rakheja D, Galindo RL, Wilson K, Amatruda JF, Cameron S. High-resolution array CGH identifies common mechanisms that drive embryonal rhabdomyosarcoma pathogenesis. Genes Chromosomes Cancer. 2011; 50:397-408.

41. Petricoin EF 3rd, Espina V, Araujo RP, Midura B, Yeung C, Wan X, Eichler GS, Johann DJ Jr, Qualman S, Tsokos M, Krishnan K, Helman LJ, Liotta LA. Phosphoprotein pathway mapping: Akt/mammalian target of rapamycin activation is negatively associated with childhood rhabdomyosarcoma survival. Cancer Res. 2007; 67:3431-3440.

42. Tostar U, Toftgard R, Zaphiropoulos PG, Shimokawa T. Reduction of human embryonal rhabdomyosarcoma tumor growth by inhibition of the hedgehog signaling pathway. Genes Cancer. 2010; 1:941-951.

43. Sekulic A, Migden MR, Oro AE, Dirix L, Lewis KD, Hainsworth JD, Solomon JA, Yoo S, Arron ST, Friedlander PA, Marmur E, Rudin CM, Chang AL, et al. Efficacy and safety of vismodegib in advanced basal-cell carcinoma. N Engl J Med. 2012; 366:2171-2179.

44. Kool M, Jones DT, Jager N, Northcott PA, Pugh TJ, Hovestadt V, Piro RM, Esparza LA, Markant SL, Remke M, Milde T, Bourdeaut F, Ryzhova M, et al. Genome sequencing of SHH medulloblastoma predicts genotype-related response to smoothened inhibition. Cancer Cell. 2014; 25:393-405.
45. Brechbiel J, Miller-Moslin K, Adjei AA. Crosstalk between hedgehog and other signaling pathways as a basis for combination therapies in cancer. Cancer Treat Rev. 2014; 40:750-759.

46. Dijkgraaf GJ, Alicke B, Weinmann L, Januario T, West K, Modrusan Z, Burdick D, Goldsmith R, Robarge K, Sutherlin D, Scales SJ, Gould SE, Yauch RL, et al. Small molecule inhibition of GDC-0449 refractory smoothened mutants and downstream mechanisms of drug resistance. Cancer Res. 2011; 71:435-444.

47. Buonamici S, Williams J, Morrissey M, Wang A, Guo R, Vattay A, Hsiao K, Yuan J, Green J, Ospina B, Yu Q, Ostrom L, Fordjour P, et al. Interfering with resistance to smoothened antagonists by inhibition of the PI3K pathway in medulloblastoma. Sci Transl Med. 2010; 2:51ra70.

48. Tang Y, Gholamin S, Schubert S, Willardson MI, Lee A, Bandopadhayay P, Bergthold G, Masoud S, Nguyen B, Vue N, Balansay B, Yu F, Oh S, et al. Epigenetic targeting of Hedgehog pathway transcriptional output through BET bromodomain inhibition. Nat Med. 2014; 20:732-740.

49. Robarge KD, Brunton SA, Castanedo GM, Cui Y, Dina MS, Goldsmith R, Gould SE, Guichert O, Gunzner JL, Halladay J, Jia W, Khojasteh C, Koehler MF, et al. GDC0449-a potent inhibitor of the hedgehog pathway. Bioorg Med Chem Lett. 2009; 19:5576-5581.

50. Raynaud FI, Eccles S, Clarke PA, Hayes A, Nutley B, Alix S, Henley A, Di-Stefano F, Ahmad Z, Guillard S, Bjerke LM, Kelland L, Valenti M, et al. Pharmacologic characterization of a potent inhibitor of class I phosphatidylinositide 3-kinases. Cancer Res. 2007; 67:5840-5850.

51. Lauth M, Bergstrom A, Shimokawa T, Toftgard R. Inhibition of GLI-mediated transcription and tumor cell growth by small-molecule antagonists. Proc Natl Acad Sci U S A. 2007; 104:8455-8460.

52. Fulda S, Sieverts H, Friesen C, Herr I, Debatin KM. The CD95 (APO-1/Fas) system mediates drug-induced apoptosis in neuroblastoma cells. Cancer Res. 1997; 57:3823-3829.

53. Walter D, Satheesha S, Albrecht P, Bornhauser BC, D'Alessandro V, Oesch SM, Rehrauer H, Leuschner I, Koscielniak E, Gengler C, Moch H, Bernasconi M, Niggli FK, et al. CD133 positive embryonal rhabdomyosarcoma stemlike cell population is enriched in rhabdospheres. PLoS One. 2011; 6:e19506.

54. Chou TC. The median-effect principle and the combination index for quantitation of synergism and antagonism. In: Chou TC, ed. Synergism and antagonism in chemotherapy. (San Diego, USA) Academic Press), 1991; pp. 61-102 